Article

\title{
Erosion Resistance and Particle Erosion-Induced Tensile Embrittlement of 3D-Selective Laser Melting Inconel 718 Superalloy
}

\author{
Jun-Ren Zhao, Fei-Yi Hung * ${ }^{(D)}$ and Truan-Sheng Lui \\ Department of Materials Science and Engineering, National Cheng Kung University, Tainan 70101, Taiwan; \\ a2x346yz03@gmail.com (J.-R.Z.); luits@mail.ncku.edu.tw (T.-S.L.) \\ * Correspondence: fyhung@mail.ncku.edu.tw; Tel.: +886-6-275-7575 (ext. 62950)
}

Received: 31 October 2019; Accepted: 20 December 2019; Published: 22 December 2019

check for updates

\begin{abstract}
We used selective laser melting (SLM) Inconel 718 (coded AS) to carry out three heat treatment processes: (1) double aging (coded A), (2) solid solution + A (coded SA), (3) homogenization + SA (coded HSA) in order to investigate the effects of microstructure changes and tensile strength enhancement on erosion resistance. The as-SLM IN718 and three heat-treated specimens were subjected to clarify the effects of erosion-induced phase transformation on tensile mechanical properties. All heat-treated specimens showed better erosion resistance than as-SLM IN718 did at all impact angles. The as-SLM IN718 and the three heat-treated specimens produced new $\gamma^{\prime}$ phase or metal-oxide via particle erosion, which increased the surface hardness of the material. The thickness of the erosion affected zone is $200 \mu \mathrm{m}$, which is the main cause of tensile embrittlement.
\end{abstract}

Keywords: Inconel 718; selective laser melting (SLM); erosion; phase transformation; tensile; embrittlement

\section{Introduction}

Inconel 718 (IN718) is widely applied in aeronautics, astronautics, and energy industries because of its excellent corrosion resistance, oxidation resistance, weldability, and mechanical properties under circumstances like room temperature and elevated temperature. Its application area includes gas turbines, turbine blades, rocket engines, components for oil and gas extraction, and nuclear engineering [1-4]. IN718 is precipitation strengthened nickel-based superalloy which could be strengthened by precipitation of D022 $\gamma^{\prime \prime}(\mathrm{Ni3Nb}), \mathrm{L} 12 \gamma^{\prime}(\mathrm{Ni3}(\mathrm{Al}, \mathrm{Ti}))$, and D0a $\delta(\mathrm{Ni3Nb})$ in the $\gamma$ matrix [5], thus could be imported in the engineering applications.

Additive manufacturing (AM) can reduce costs, save mold manufacturing costs, and create complex geometric shapes. It has been applied to various industries [6]. Selective laser melting (SLM) is classified as the family of AM technologies. SLM uses metal powder as raw material to be illuminated by a high-energy laser beam within a specified area. After the powder melts, it is rapidly solidified at high cooling rates [7-9].

Blades, turbines, and engines are often impacted by solid particle erosion wear, resulting in damage to pieces and equipment. Erosion wear is the phenomenon of gas or liquid-driven particles striking the surface of a material $[10,11]$. Few articles mention the particle erosion wear of nickel-based superalloys. Most of them concern their casting and forging [12-14]. We are interested in particle erosion resistance and the erosion induced phase transformation of 3D-printed IN718.

Particle erosion wear could induce phase transformation. This phenomenon has been confirmed by Al-Si-Mg alloy [15], austempered ductile iron (ADI) [16], 316 stainless steel [17], and even 3D-printed Ti-6Al-4V [18]. The heat generated by particle impact or strain helps dissolve a phase or form a new phase, further affecting the hardness and other mechanical properties. 
Based on this, the purpose of this study is to investigate the microstructure and the mechanical properties of heat-treated SLM Inconel 718. To clarify the erosion-induced phase transformation mechanism and its effect on the material brittleness, we compared the particle erosion wear behavior of as-SLM Inconel 718 with those of three heat-treated specimens. These results have significant reference value for the aerospace industry.

\section{Experimental Procedure}

The purpose of the experiments was to compare the erosion resistance of as-SLM specimen (coded AS) with those of the three heat-treated specimens (A, SA, and HSA) under various impact angles. Table 1 shows the SLM process parameters used in this study. The raw material IN718 powder supplied by EOS GmbH (Electro-Optical Systems, Krailling, Germany) had an average particle size of $15 \mu \mathrm{m}$ (Figure 1). The chemical compositions of IN718 included: Ni (50-55 wt. \%), Cr (17-21 wt. \%), Nb (4.7-5.5 wt. \%), Ti (0.6-1.2 wt. \%), Al (0.2-0.8 wt. \%), Mo (2.8-3.3 wt. \%), Co ( $\leq 1.0$ wt. \%), Cu ( $\leq 0.3$ wt. $\%), C(\leq 0.08$ wt. \%), and Fe (bal.).

Table 1. Process parameters used for selective laser melting (SLM).

\begin{tabular}{cccccc}
\hline $\begin{array}{c}\text { Laser } \\
\text { Power }\end{array}$ & $\begin{array}{c}\text { Scanning } \\
\text { Velocity }\end{array}$ & $\begin{array}{c}\text { Layer } \\
\text { Thickness }\end{array}$ & $\begin{array}{c}\text { Hatching } \\
\text { Space }\end{array}$ & $\begin{array}{c}\text { Idle } \\
\text { Time }\end{array}$ & $\begin{array}{c}\text { Preheat } \\
\text { Temperature }\end{array}$ \\
\hline $230 \mathrm{~W}$ & $760 \mathrm{~mm} / \mathrm{s}$ & $40 \mu \mathrm{m}$ & $110 \mu \mathrm{m}$ & $10 \mathrm{~s}$ & $80^{\circ} \mathrm{C}$ \\
\hline
\end{tabular}

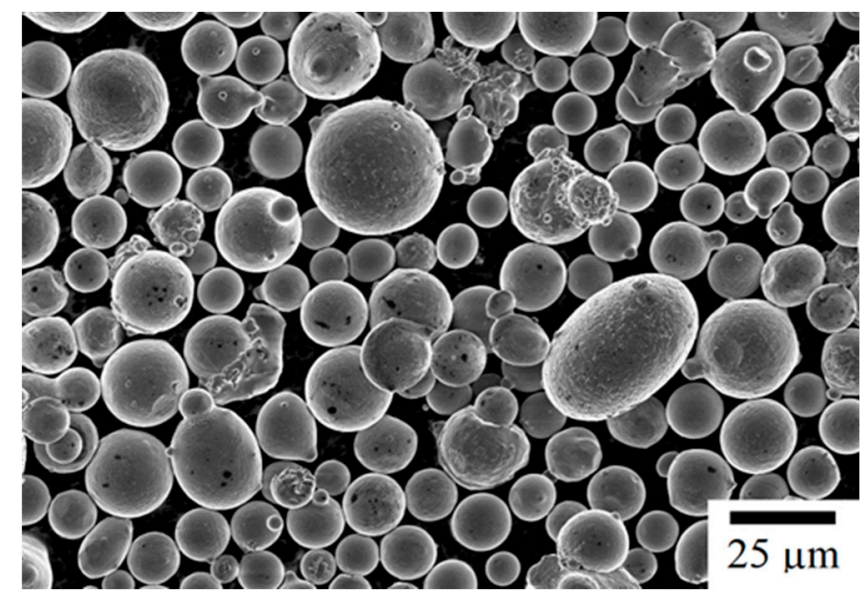

Figure 1. The morphology of Inconel 718 (IN718) powder.

The specimens were removed from the support by electrical discharge machining wire cutting. The as-SLM IN718 (shortly "AS") specimen was subjected to three heat treatment processes: (1) " $\mathrm{A}^{\prime}$ : double aging treatment $\left(720^{\circ} \mathrm{C}\right.$ for $8 \mathrm{~h}$, then furnace cooling at $55^{\circ} \mathrm{C} / \mathrm{h}$ to $620^{\circ} \mathrm{C}$, maintaining $620^{\circ} \mathrm{C}$ for $8 \mathrm{~h}$, finally air cooling); (2) "SA": solid solution treatment $\left(980^{\circ} \mathrm{C}\right.$ for $1 \mathrm{~h}$, then water cooling) followed by " $\mathrm{A}$ "; and (3) "HSA": homogenization treatment $\left(1080^{\circ} \mathrm{C}\right.$ for $1.5 \mathrm{~h}$, then air cooling) followed by "SA".

The equipment used for the erosion test is shown in Figure 2. We used $\mathrm{Al}_{2} \mathrm{O}_{3}$ particles as impact particle with an average size of $450 \mu \mathrm{m}$ for the erosion tests. Their morphology is shown in Figure 3. The specimens were polished with SiC paper from \#80 to \#1000, then were soaked in acetone for ultrasonic cleaning before the erosion tests. Two hundred grams of the erosion particles were used under a compressed air flow of $3 \mathrm{~kg} / \mathrm{cm}^{2}(0.29 \mathrm{MPa})$. The impact angles were set to $15^{\circ}, 30^{\circ}, 45^{\circ}, 60^{\circ}$, $75^{\circ}$, and $90^{\circ}$. 


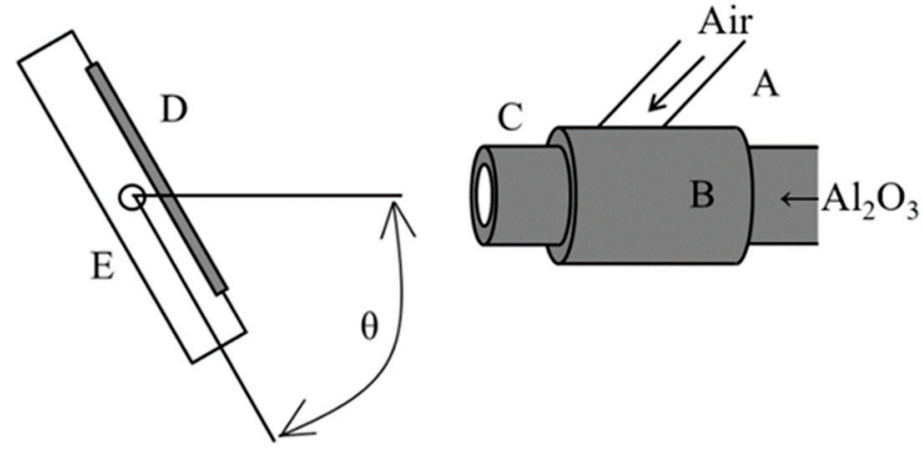

Figure 2. The equipment for particle erosion test. (A: compressed air flow; B: erosion particle $\left(\mathrm{Al}_{2} \mathrm{O}_{3}\right)$ supplier; C: erodent nozzle; D: specimen; E: specimen holder; $\theta$ : impact angle.)

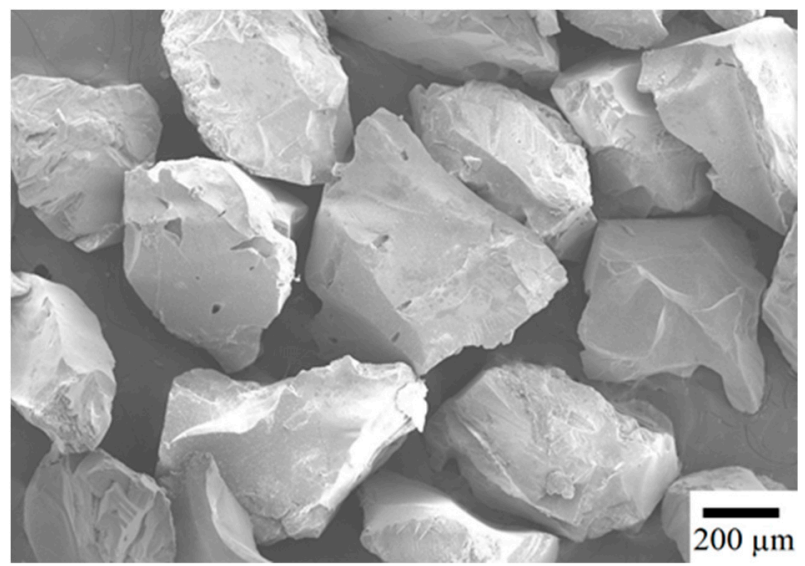

Figure 3. The morphology of the $\mathrm{Al}_{2} \mathrm{O}_{3}$ erosion particles.

After the erosion test, the specimens were polished with $\mathrm{SiC}$ paper (from \#80 to \#5000). Then they were soaked in $\mathrm{Al}_{2} \mathrm{O}_{3}$ aqueous solution ( 1 and $0.3 \mu \mathrm{m}$ ), and a $0.04 \mu \mathrm{m} \mathrm{SiO} \mathrm{S}_{2}$ polishing solution. Finally, they were etched with a chemical solution consisting of $50 \% \mathrm{HCl}, 10 \% \mathrm{HNO}_{3}, 2 \% \mathrm{HF}$, and $38 \%$ of distilled water. Optical microscopy (OM, OLYMPUS BX41M-LED, Tokyo, Japan) and a scanning electron microscope (SEM, HITACHI SU-5000, HITACHI, Tokyo, Japan) were used to examine the surface and the subsurface of the erosion specimens.

The specimens eroded at the $90^{\circ}$ impact angle were selected to analyze the phase composition pre and post erosion states by X-ray diffractometry (XRD, Bruker AXS GmbH, Karlsruhe, Germany). Transmission electron microscopy (TEM, Tecnai F20 G2, EFI, Hillsboro, OR, USA) was used to investigate the microstructure characteristics of the A and HSA pre and post erosion states since the difference in microstructure between these two is the most significant. Finally, the Vickers hardness test (Shimadzu HMV-2000L, Shimadzu, Kaohsiung, Taiwan) was used to analyze the microhardness distribution along the longitudinal direction after the erosion.

The dimensions of the SLM IN718 tensile specimen are shown in Figure 4. The parallel sections of the AS and the three heat-treated specimens were eroded by $200 \mathrm{~g} \mathrm{Al}_{2} \mathrm{O}_{3}$ particles under a compressed air flow of $3 \mathrm{~kg} / \mathrm{cm}^{2}(0.29 \mathrm{MPa})$ at the $90^{\circ}$ impact angle. The room temperature tensile tests of the pre and post erosion states were performed by a universal testing machine (HT-8336, Hung Ta, Taichung, Taiwan). The crosshead speed was chosen as $1 \mathrm{~mm} / \mathrm{min}$, corresponding to the initial strain rate of 8.33 $\times 10^{-4} \mathrm{~s}^{-1}$. There were at least three specimens used for each tensile test, and the tensile results were taken as the mean values produced by those specimens. 


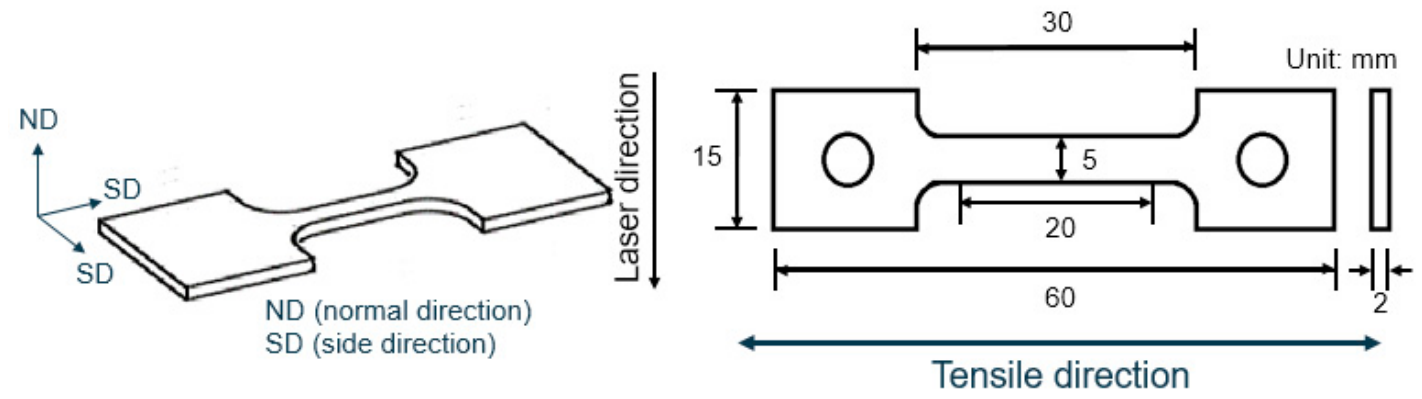

Figure 4. Schematic diagram of the selective laser melting (SLM) IN718 tensile specimen.

\section{Results and Discussion}

\subsection{Particle Erosion Wear Characteristics and Mechanisms}

Figure 5 shows the microstructure of the as-SLM Inconel 718 and the three strength-enhanced heat-treated specimens. The as-SLM (AS) specimen has a layered melt pool structure as shown in Figure $5 \mathrm{a}$. Figure $5 \mathrm{~b}$ shows the microstructure of the specimen " $\mathrm{A}$ ". We can observe long grains penetrating the melt pools, while the melt pool traces are inconspicuous because of thermal diffusion. Figure $5 c$ shows the microstructure of the specimen "SA". The melt pool traces and the dendritic structure are replaced by long grains parallel to the laser direction. This means that after the solid solution treatment, the dendrites decomposed, and the segregated solute atoms dissolved into the matrix to form long recrystallized grains. The microstructure of the specimen "HSA" is shown in Figure $5 \mathrm{~d}$. The HSA specimen exhibits passivated equiaxed recrystallized grains. These four microstructures are similar to those mentioned in the literature [19-22].
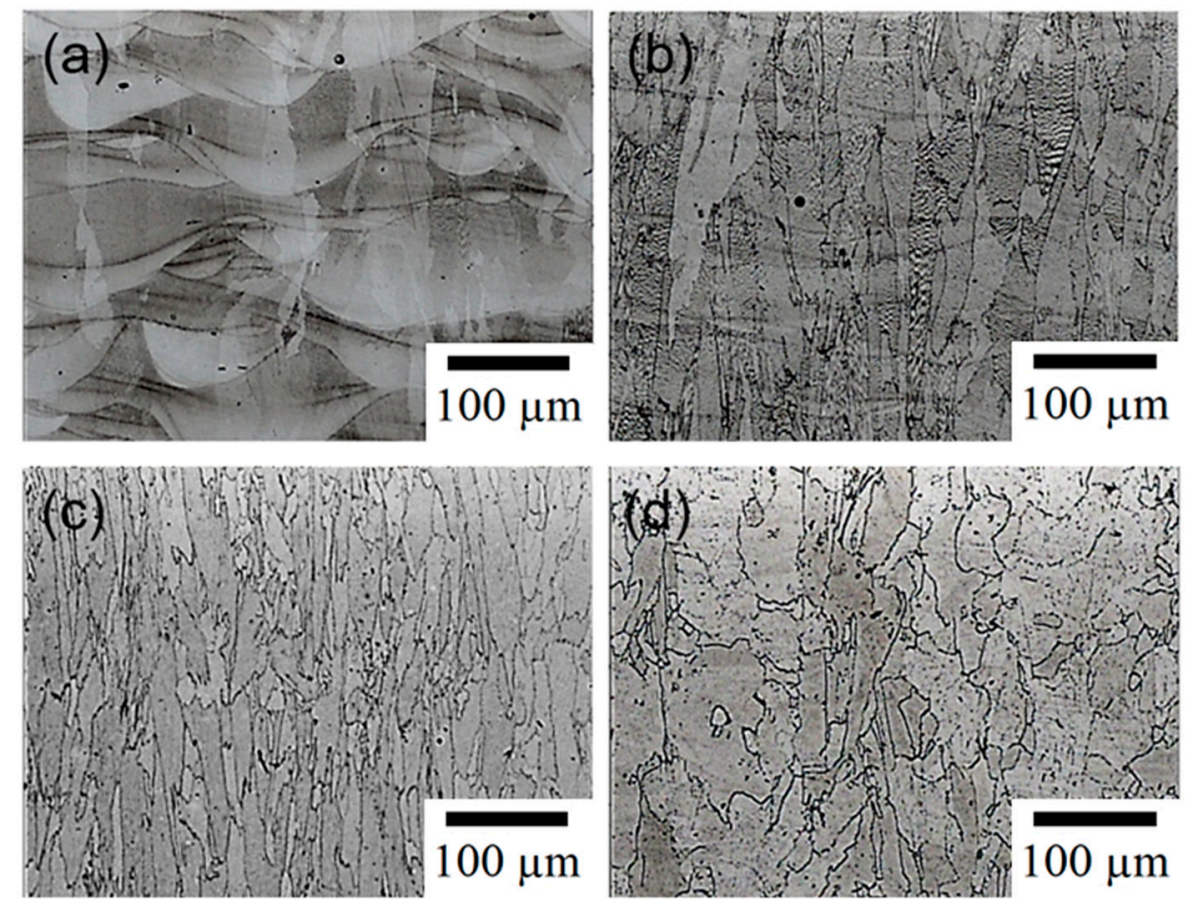

Figure 5. Microstructures of (a) AS, (b) A, (c) SA, and (d) HSA. (AS: as-SLM; A: double aging treatment $\left(720^{\circ} \mathrm{C}\right.$ for $8 \mathrm{~h}$, then furnace cooling at $55^{\circ} \mathrm{C} / \mathrm{h}$ to $620^{\circ} \mathrm{C}$, maintaining $620^{\circ} \mathrm{C}$ for $8 \mathrm{~h}$, finally air cooling); SA: solid solution treatment $\left(980^{\circ} \mathrm{C}\right.$ for $1 \mathrm{~h}$, then water cooling) followed by A; HSA: homogenization treatment $\left(1080{ }^{\circ} \mathrm{C}\right.$ for $1.5 \mathrm{~h}$, then air cooling) followed by SA.).

According to previous literature $[23,24]$, the maximal erosion rates of general ductile metals often take place at about $20-30^{\circ}$ angles, but the maximal erosion wear rate of brittle materials (ceramics and 
glass) occurs at about a $90^{\circ}$ angle. The erosion rates of the AS, A, SA, and HSA specimens are displayed in Figure 6. All specimens attain a maximal erosion rate at $30^{\circ}$ angle, and a minimal erosion rate at $90^{\circ}$ angle. The erosion rates decrease with impact angle, which means that ductile-cutting dominates the erosion behavior. At all impact angles, the erosion rate of AS was higher than those of A, SA, and HSA, indicating that heat treatment, especially double aging treatment, can significantly improve the erosion resistance of SLM IN718. In this system, the erosion resistance of the SLM specimen was better than the commercial rolling specimen.

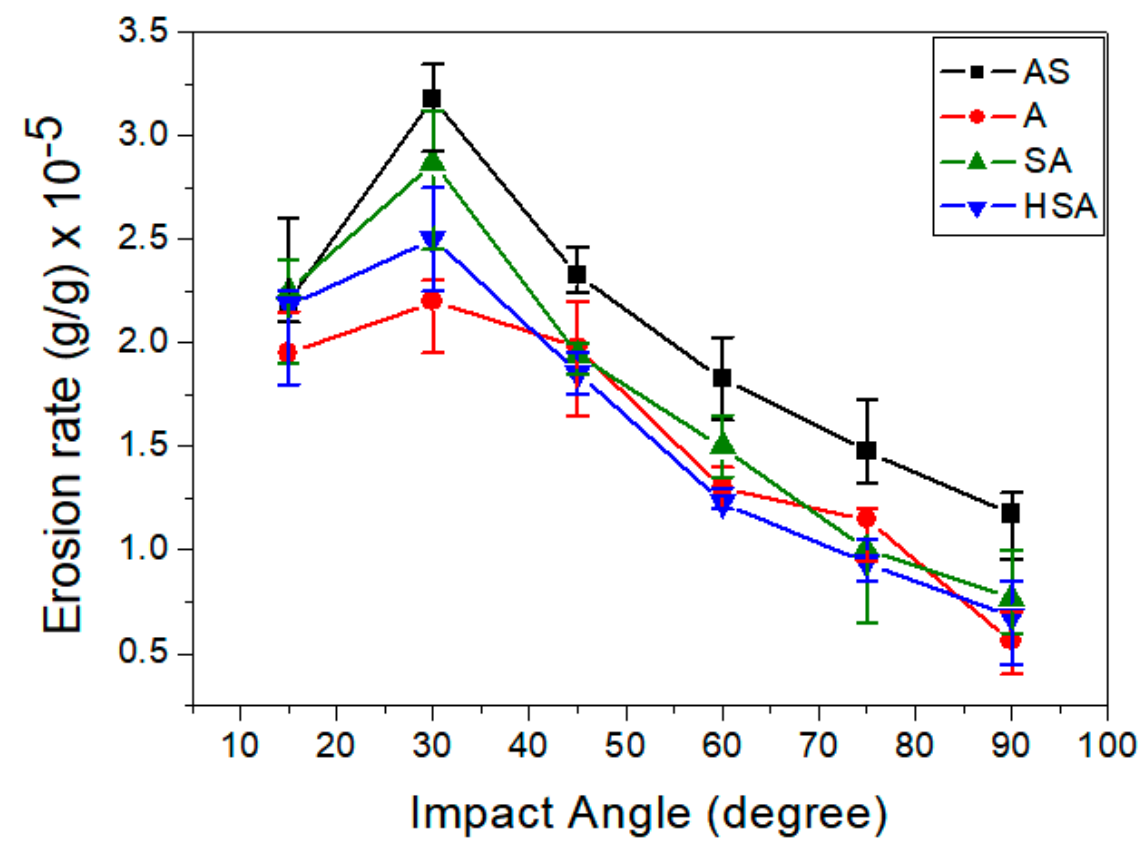

Figure 6. The erosion rates as a function of impact angle.

The difference in the erosion rates among the specimens culminated at $30^{\circ}$, and it was significant in the low-angle region $\left(<45^{\circ}\right)$, the domain of ductile domination. The erosion rates from high to low corresponded to AS, SA, HSA, and A. However, in the high-angle region $\left(>45^{\circ}\right)$, the domain of brittle domination, the erosion rates of A, SA, and HSA were similar to each other, and significantly lower than that of AS.

For an explanation, we turn to Figure 7 showing the surface morphology of specimens at $30^{\circ}, 60^{\circ}$, and $90^{\circ}$ angles. All specimens have lips and grooves on the erosion surface proportional to the erosion rate. The surface of AS has the most amount of lips and grooves, while A has the least. This means that below $45^{\circ}$, the erosion rate is positively correlated with the material being scraped off by erosion particles. At both $60^{\circ}$ and $90^{\circ}$, AS exhibited a ductile scraped and squeezed morphology, different from those of the heat-treated specimens with a brittle pit morphology.

The subsurface morphology of all specimens at $30^{\circ}, 60^{\circ}$, and $90^{\circ}$ are shown in Figure 8 . Specimen A had the lowest erosion rate with almost no lips, showing a smoother subsurface morphology. The subsurface morphology of A, SA, and HSA were more undulated. At $60^{\circ}$, AS and A exhibited similar subsurface morphology, with some lip features and oblique pits; SA and HSA were filled with oblique pits without lips. At $90^{\circ}$, narrow and deep pits were observed in AS, while A, SA, and HSA had wider and shallow pits. In addition, extrusion traces after the positively eroded particles were observed in SA and HSA, with the latter one being more obvious. 


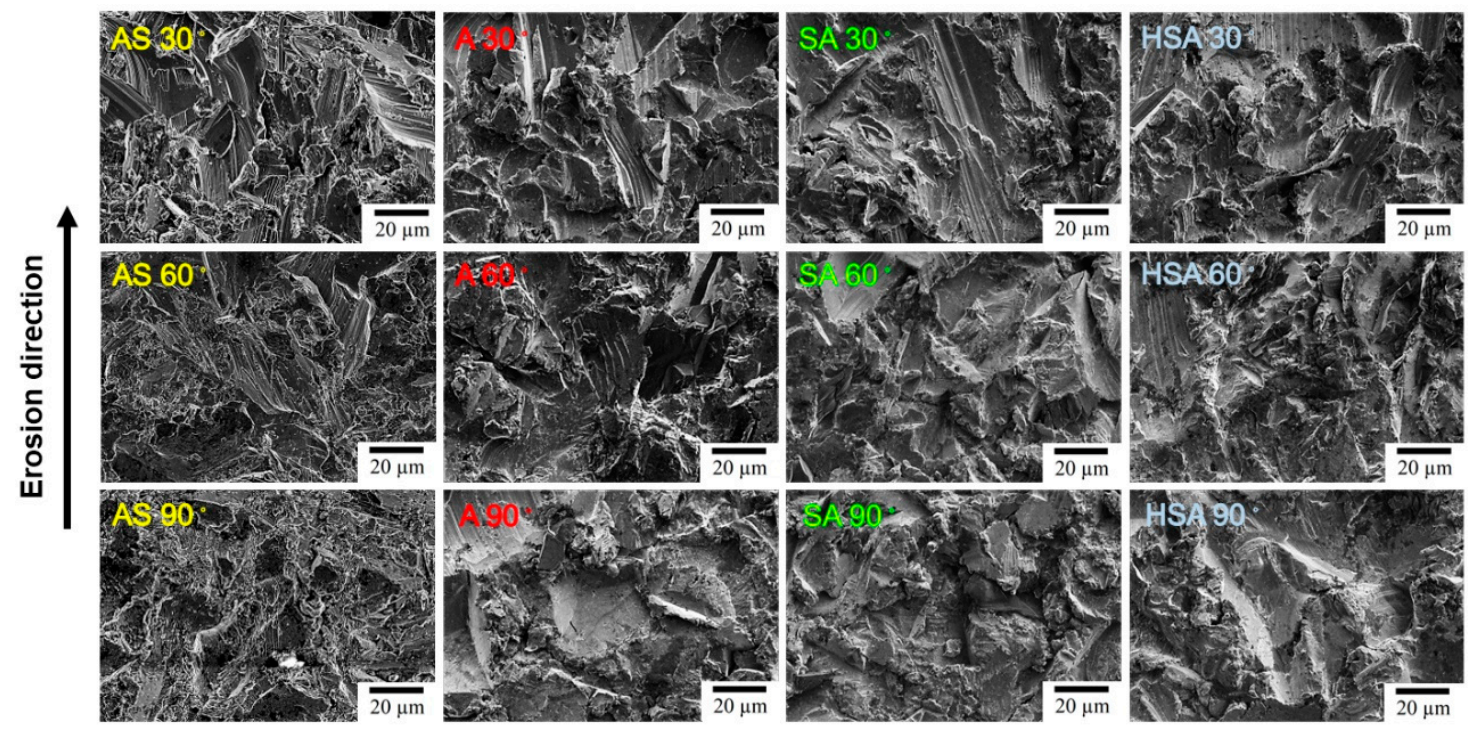

Figure 7. Surface morphology of AS, A, SA, and HSA at various impact angles.
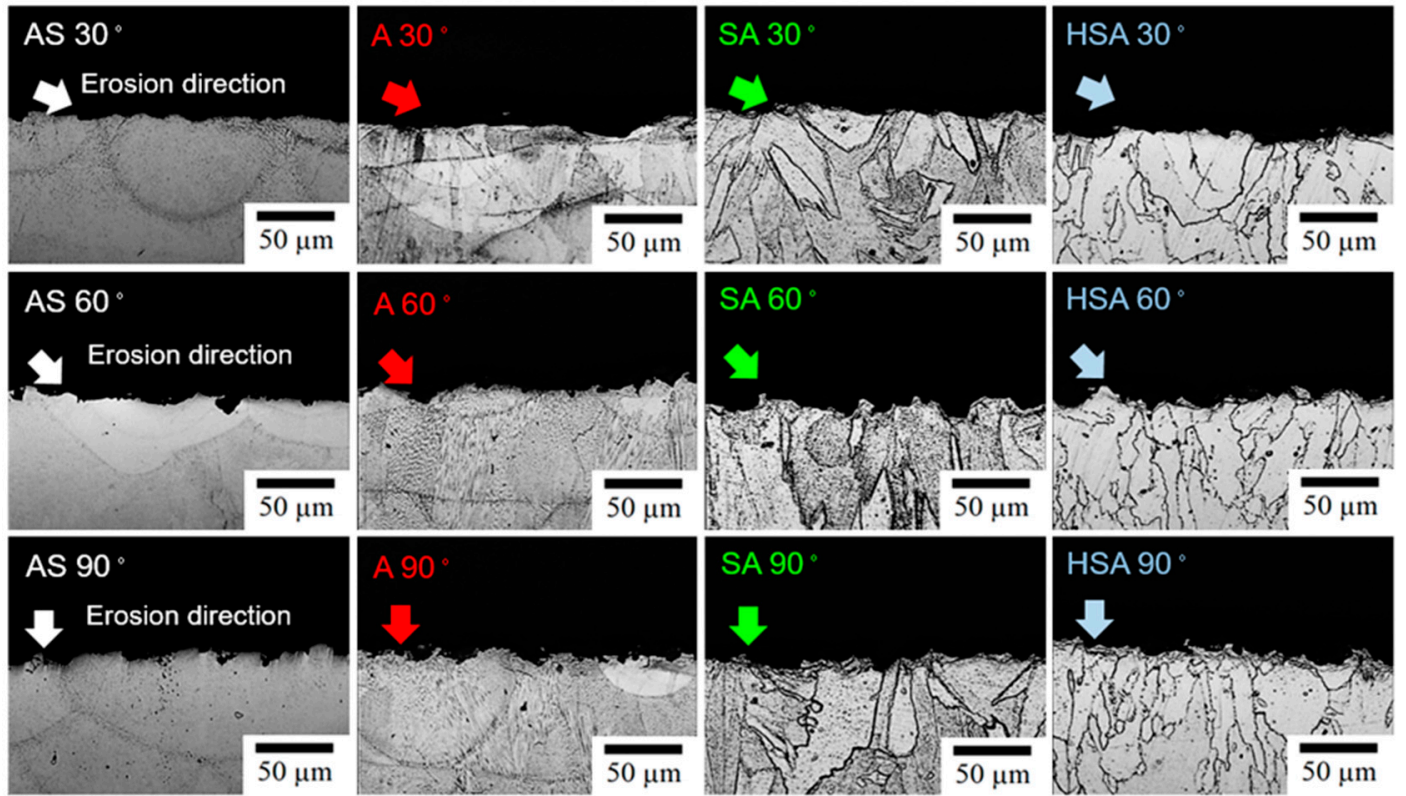

Figure 8. Subsurface morphology of AS, A, SA, and HSA at various impact angles.

\subsection{Particle Erosion Induced Phase Transformation}

Figure 9 displays the XRD diffraction analysis pre and post positive erosion endured at $90^{\circ}$. For post erosion labeling, we added an ' $\mathrm{E}$ ' after the codes, i.e., ASE, AE, SAE, and HSAE. We can observe five peaks, namely (111), (200), (220), (311), and (222). As the peaks of $\gamma, \gamma^{\prime}$, and $\gamma^{\prime \prime}$ are almost overlapping, it is difficult to match peaks with phases. The literature $[5,25]$ suggests, to match the (111) peak with the $\gamma$ phase and the (222) peak with the $\gamma^{\prime}$ phase. The main peaks of A, SA, and HSA appear as (111) peaks, while the (222) peaks are more obvious than in the AS, indicating that the $\gamma^{\prime}$ phase was formed after heat treatments. 


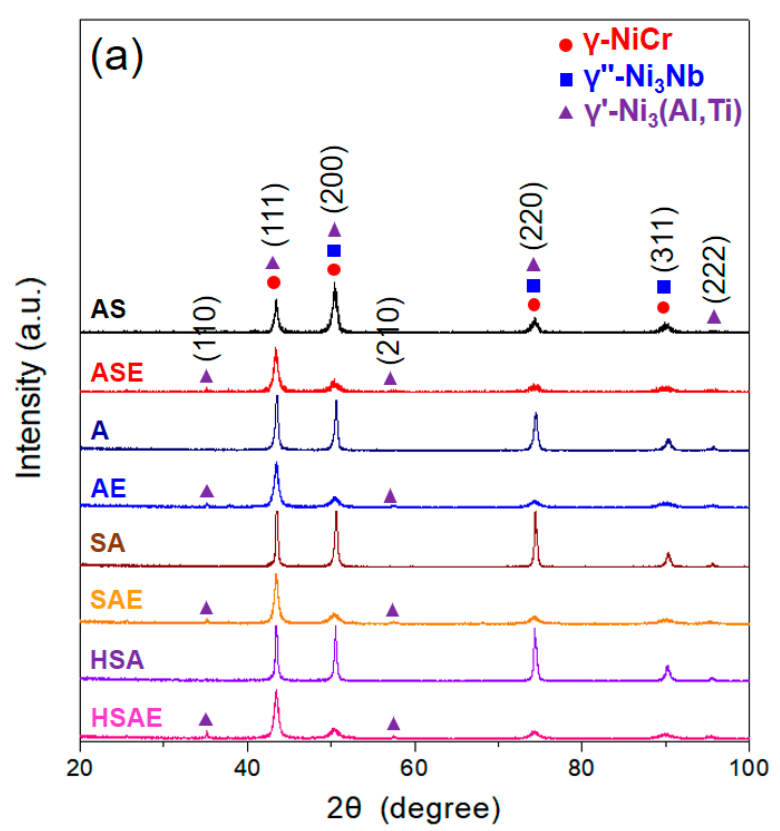

(b)

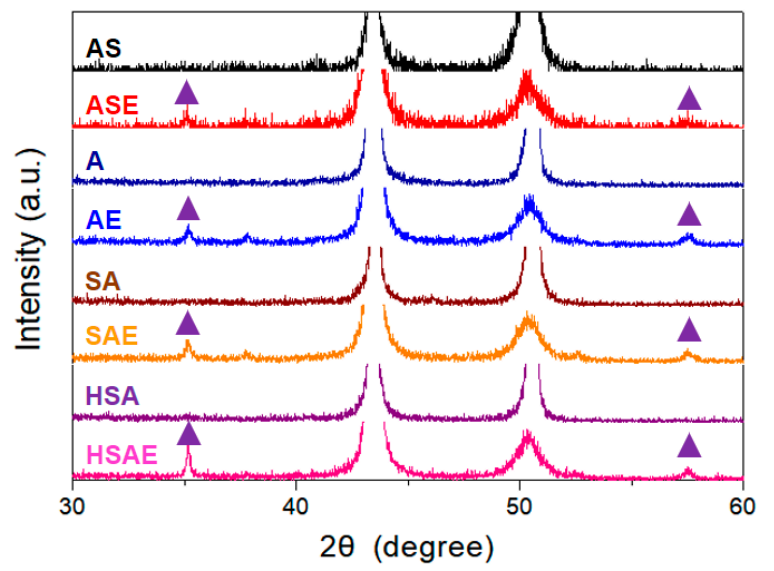

Figure 9. X-ray diffraction pattern of AS, A, SA, and HSA pre and post erosion: (a) $20-100^{\circ}$, and (b) $30-60^{\circ}$.

In addition, the orientation was changed, and several new peaks appeared after erosion. The new $\gamma^{\prime}$ phase and metal-oxide (MO) were generated. Meanwhile, these peaks are in agreement with $\mathrm{Al}_{2} \mathrm{O}_{3}$ corundum, meaning that there may be some residual $\mathrm{Al}_{2} \mathrm{O}_{3}$ phase left in the surface of the material.

We compared the changes of microstructures of A, AE, HSA, and HSAE between pre and post erosion (AE and HSAE) via TEM. Figure 10a is the bright field TEM image of the specimen A surface region. From the selected area electron diffraction (SAED) pattern shown in Figure 10b, it can be confirmed that the black and the white regions both represent $\gamma$ phase matrices. Figure $10 \mathrm{c}$ displays the bright field TEM image of the surface region of the HSA specimen. The SAED pattern of the white area corresponds a $\gamma$ phase matrix, shown in Figure $10 \mathrm{~d}$.

Figure 11a,b shows bright field TEM images of the surface region of AE and HSAE, respectively. The microstructures are completely different after the particle erosion. Figure 11c,d displays the well-defined SAED ring patterns of AE and HSAE, respectively. The fine grains within the region selected indicate that the surface regions of both A and HSA transformed post erosion. 

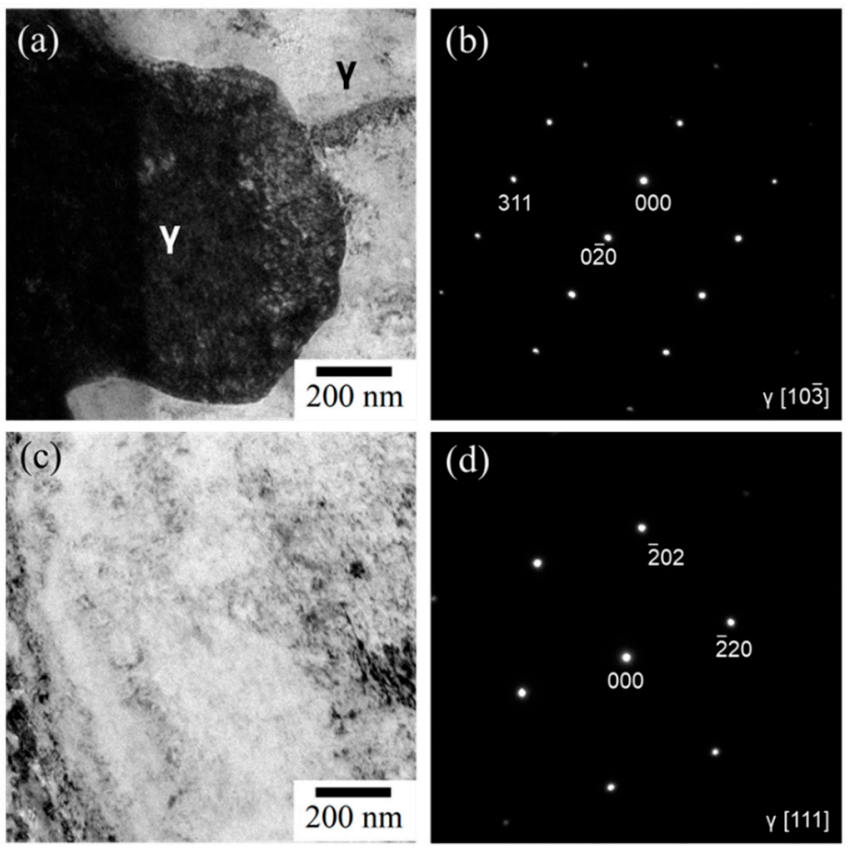

Figure 10. Transmission electron microscopy (TEM) images of specimens pre erosion: (a) A, (b) SAED (selected area electron diffraction) pattern of A, (c) HSA, and (d) SAED pattern of HSA.
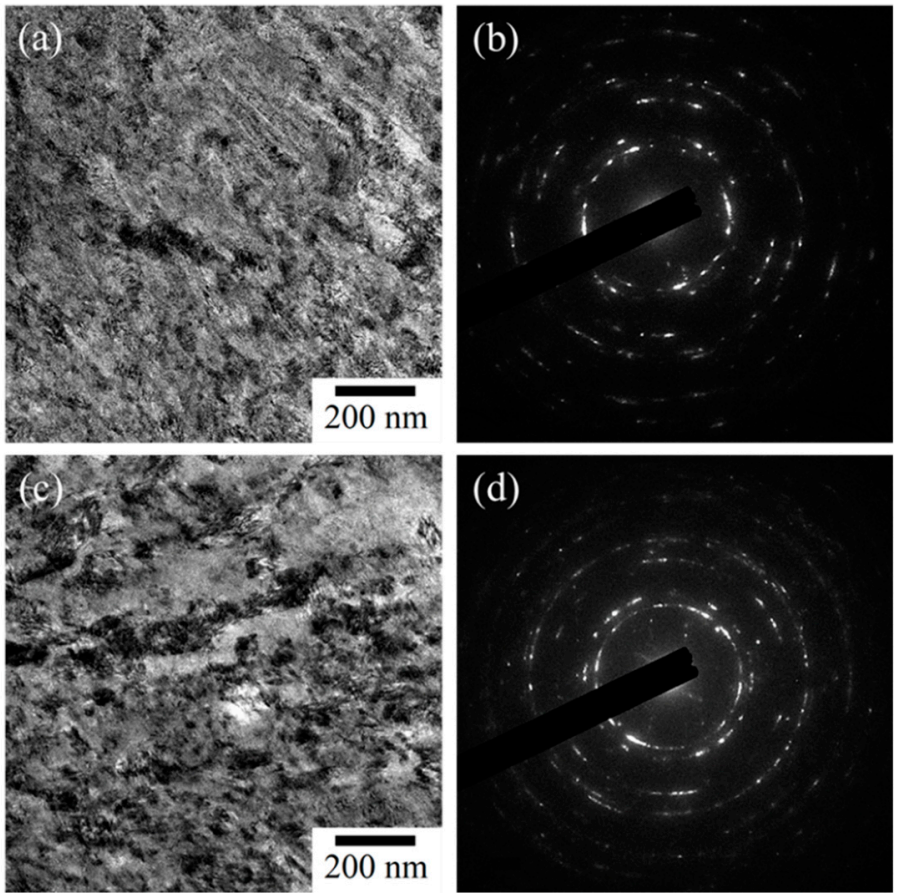

Figure 11. TEM images of specimens after erosion: (a) AE, (b) SAED pattern of AE, (c) HSAE, and (d) SAED pattern of HSAE.

In addition, when $\mathrm{Al}_{2} \mathrm{O}_{3}$ particles impact the surface of $\mathrm{Ni}$-alloy specimen, it can induce impact-heat up to $\approx 500{ }^{\circ} \mathrm{C}$ and small sparks are also found during the erosion process. Furthermore, the aging precipitation temperature of the Ni alloy of this paper is about $600^{\circ} \mathrm{C}$. Based on our XRD and TEM: after erosion, the crystallization characteristics of the surface of the test specimen are different (including orientation changes, and metal-oxide formations).

The microhardness distribution along the longitudinal direction of the specimens post particle erosion is shown in Figure 12. After positive erosion, the specimens can be divided into two zones. 
The erosion affected zone (EAZ) runs from the erosion surface toward the bottom, while the hardness stability zone (matrix zone) being located below the EAZ. At EAZ, microhardness gradually declines from the surface to a depth of $200 \mu \mathrm{m}$, where it reaches the matrix hardness stability zone.

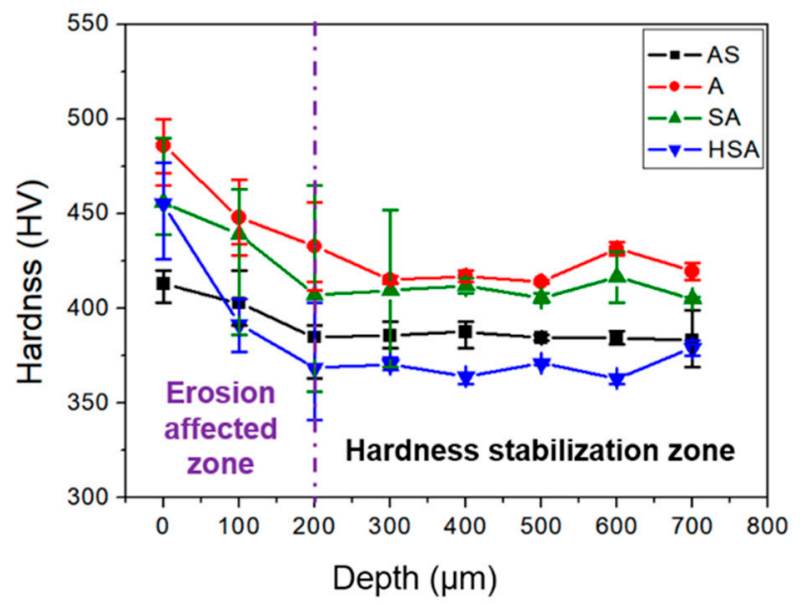

Figure 12. Microhardness distribution of ASE, AE, SAE, and HSAE in the longitudinal direction.

According to previous studies [15-18], temperature increase on the impacted specimen surface induces phase transformation. Wood [17] and Zhao [18] described that erosion would lead to high temperature, making the phase dissolve and the surface layer soft. However, this phenomenon did not occur during our observations. Instead, the surface hardness increased, which can be attributed to that of IN718 is precipitation hardened superalloy. The particle erosion resulted in heat-induced phase transformation, yielding a new $\gamma^{\prime}$ phase, which composite with work hardening owing to the eroded particles.

There is a difference between the surface hardness and the stable hardness of the specimens. This difference was maximal in the case of the HSA specimen. Our interpretation is that the HSA specimen had its surface squeezed down and stacked by erosion particles (see Figure 8). The structural evolution of the material after erosion has a significant effect on the tensile mechanical properties of the specimen.

\subsection{Influence of Erosion Induced Phase Transformation on Mechanical Properties}

Figure 13 shows the stress-strain curve of the four specimens pre and post positive erosion at a $90^{\circ}$ impact angle. The tensile strength of A, SA, and HSA improved significantly, while the ductility reduced after heat treatments. After the positive erosion, the stress-strain curves of the four specimens shifted to the right slide, the ductility also reduced significantly.

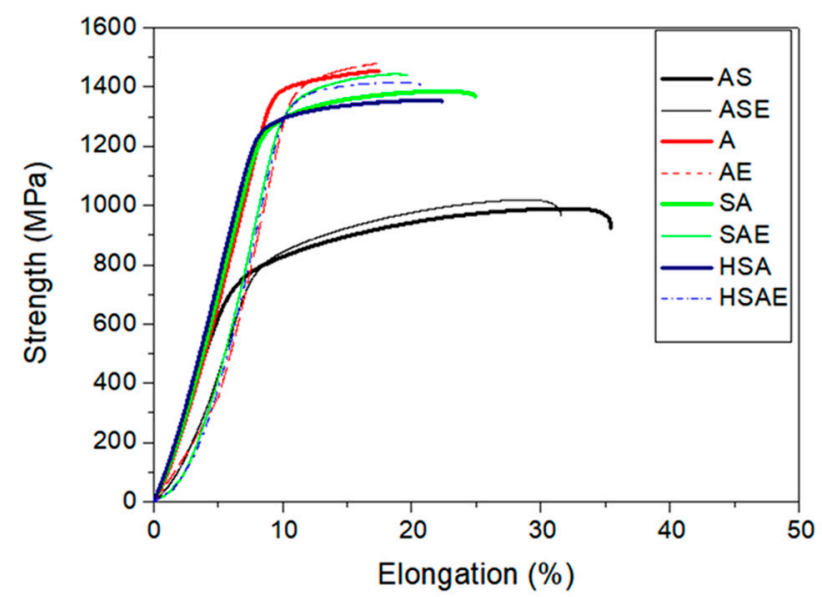

Figure 13. Stress-strain curve of specimen pre and post positive erosion. 
Figure 14 shows the tensile mechanical proprieties of the four specimens pre and post positive erosion at a $90^{\circ}$ impact angle. The AS specimen had better ductility (UE close to 30\%), but the strength was lower than that in the ASM 5662 standard [26] for direct applicability. The strength obviously increased, and the ductility significantly reduced after three heat treatments. The strength of ASE, AE, SAE, and HSAE were similar to those pre erosions, but ductility is significantly reduced, and embrittlement occurred.
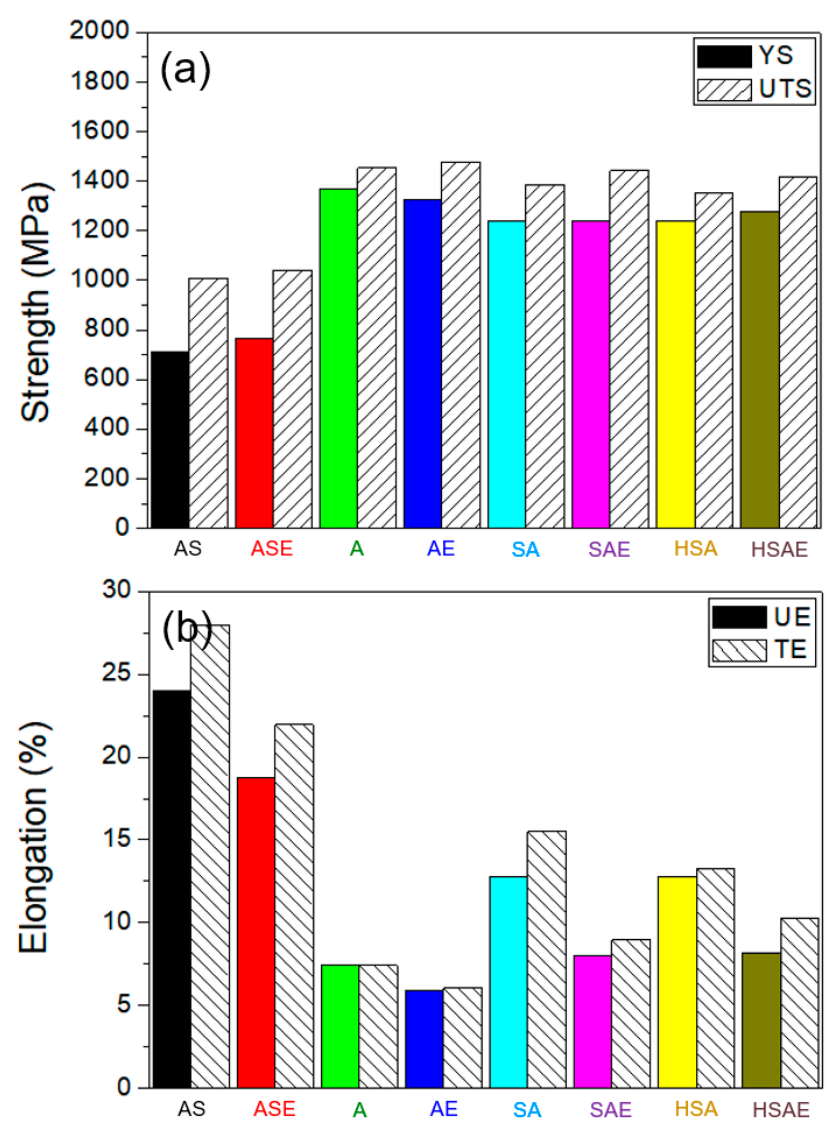

Figure 14. Tensile properties of specimen pre and post positive erosion: (a) strength, (b) ductility.

Figure 15 displays the SLM-IN718 phase transformation after erosion. According to previous research [27-29], deformation at a moderate temperature promotes the precipitated of strengthening phases. The heat generated by particle impact during erosion increases the surface temperature. The deformation caused by the extrusion lets the $\gamma^{\prime}$ phase precipitate into the $\gamma$ matrix, thereby increasing the hardness of EAZ. Figure 12 suggests that the erosion induced phase transformation precipitates the hard $\gamma^{\prime}$ phase, generates MO in the surface erosion zone and enhances the hardness of EAZ.

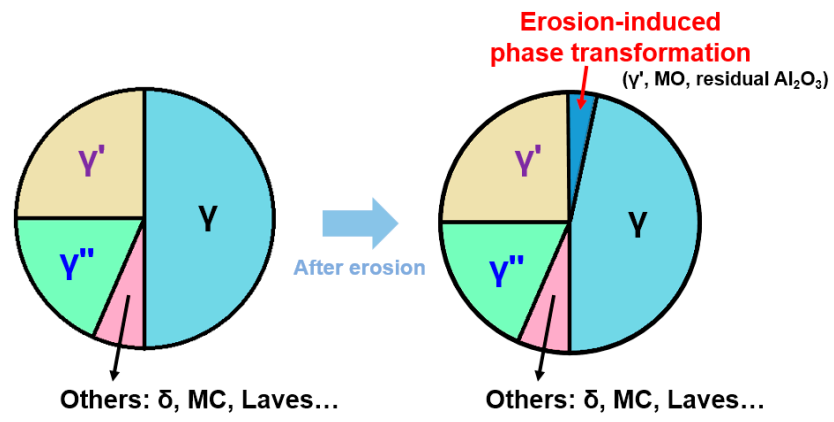

Figure 15. Schematic diagram of the IN718 phase transformation between pre and post erosion. 
The precipitation behavior of the double aging heat treatment causes a large decrease in ductility (Figure 14). This effect is similar to the ductility reducing mechanism of the erosion induced precipitation of the $\gamma^{\prime}$ phase. Based on this, it can be confirmed that the phase transformation occurs on the IN718 specimen surface post particle erosion, and increases the amount of erosion (see Figure 16), resulting in the tensile ductility decreases and the erosion embrittlement effect occurs.
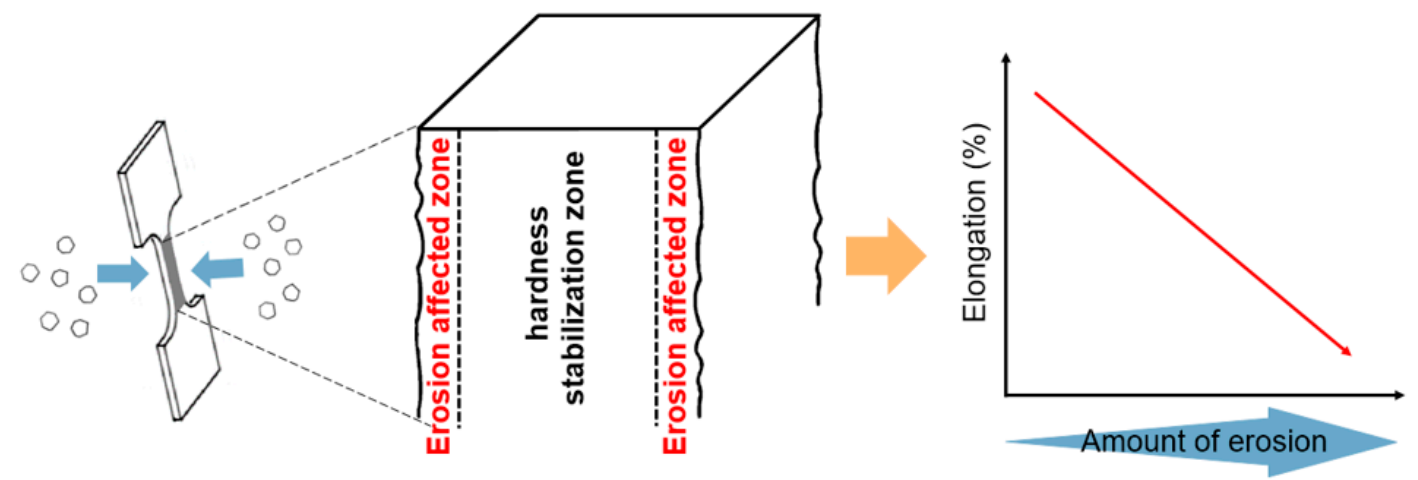

Figure 16. Decrease in ductility caused by the impact of erosion particles.

\section{Conclusions}

1. The maximal corrosion rate of AS, A, SA, and HSA occurred at a $30^{\circ}$ angle, while the lowest one occurred at $90^{\circ}$. This corresponds to the dominant corrosion behavior of ductile cutting. Heat treatment, especially double aging heat treatment, could increase erosion resistance. In the ductile domination region $\left(<45^{\circ}\right)$, the difference of increasing was remarkable, which positively correlated with the ductility of each specimen. In the brittle domination region $\left(>45^{\circ}\right)$, the erosion rates of $\mathrm{A}, \mathrm{SA}$, and HSA remained similar. In this system, the erosion resistance of the SLM specimen was better than the commercial rolling specimen.

2. After particle erosion, orientation changes and phase transformation occurs to generate $\gamma^{\prime}$ phase or $\mathrm{MO}$. With the work-hardening effect induced by the impact of $\mathrm{Al}_{2} \mathrm{O}_{3}$ particles, the specimens obtained their highest hardness at the surface region.

3. After heat treatment, the strength of SLM IN718 increased, while ductility decreased. The double aging heat treatment precipitated $\gamma^{\prime}$ to enhance the strength and reduce the ductility. After erosion, orientation change and phase transformation to generate $\gamma^{\prime}$ phase or MO on both sides of EAZ, the tensile strength merely varied a little, yet tensile embrittlement occurred.

Author Contributions: Methodology, J.-R.Z.; investigation, J.-R.Z.; data curation, J.-R.Z.; writing-original draft preparation, J.-R.Z.; writing-review and editing, F.-Y.H. and T.-S.L.; supervision, F.-Y.H. and T.-S.L. All authors have read and agreed to the published version of the manuscript.

Funding: This research received no external funding.

Acknowledgments: The authors are grateful to The Instrument Center of National Cheng Kung University and the Ministry of Science and Technology of Taiwan (Grant No. MOST 107-2221-E-006-012-MY2) for their financial support for this research.

Conflicts of Interest: The authors declare no conflict of interest.

\section{References}

1. Strondl, A.; Fischer, R.; Frommeyer, G.; Schneider, A. Investigations of MX and $\gamma^{\prime} / \gamma^{\prime \prime}$ precipitates in the nickel-based superalloy 718 produced by electron beam melting. Mater. Sci. Eng. A 2008, 480, 138-147. [CrossRef]

2. Hong, C.; Gu, D.; Dai, D.; Gasser, A.; Weisheit, A.; Kelbassa, I.; Zhong, M.; Poprawe, R. Laser metal deposition of TiC/Inconel 718 composites with tailored interfacial microstructures. Opt. Laser Technol. 2013, 54, 98-109. [CrossRef] 
3. Murr, L.E.; Martinez, E.; Gaytan, S.M.; Ramirez, D.A.; Machado, B.I.; Shindo, P.W.; Martinez, J.L.; Medina, F.; Wooten, J.; Ciscel, D.; et al. Microstructural Architecture, Microstructures, and Mechanical Properties for a Nickel-Base Superalloy Fabricated by Electron Beam Melting. Metall. Mater. Trans. A 2011, 42, 3491-3508. [CrossRef]

4. Kistler, N.A. Characterization of Inconel 718 Fabricated through Powder Bed Fusion Additive Manufacturing. Bachelor's Thesis, The Pennsylvania State University, University Park, PA, USA, 2015.

5. Strößner, J.; Terock, M.; Glatzel, U. Mechanical and Microstructural Investigation of Nickel-Based Superalloy IN718 Manufactured by Selective Laser Melting (SLM). Adv. Eng. Mater. 2015, 17, 1099-1105. [CrossRef]

6. Sun, J.F.; Yang, Y.Q.; Wang, D. Parametric optimization of selective laser melting for forming Ti6Al4V samples by Taguchi method. Opt. Laser Technol. 2013, 49, 118-124. [CrossRef]

7. Shiomi, M.; Osakada, K.; Nakamura, K.; Yamashita, T.; Abe, F. Residual Stress within Metallic Model Made by Selective Laser Melting Process. CIRP Ann. 2004, 53, 195-198. [CrossRef]

8. Mercelis, P.; Kruth, J.P. Residual stresses in selective laser sintering and selective laser melting. Rapid Prototyp. J. 2006, 12, 254-265. [CrossRef]

9. Liu, F.; Lin, X.; Yang, G.; Song, M.; Chen, J.; Huang, W. Microstructure and residual stress of laser rapid formed Inconel 718 nickel-base superalloy. Opt. Laser Technol. 2011, 43, 208-213. [CrossRef]

10. Finnie, I. Some observations on the erosion of ductile metals. Wear 1973, 23, 87-96. [CrossRef]

11. Dai, W.S.; Chen, L.H.; Lui, T.S. A study on $\mathrm{SiO}_{2}$ particle erosion of flake graphite and spheroidal graphite cast irons. Wear 2000, 239, 143-152. [CrossRef]

12. Shanov, V.; Tabakoff, W. Erosion resistance of coatings for metal protection at elevated temperatures. Surf. Coat. Technol. 1996, 86-87, 88-93. [CrossRef]

13. Mishra, S.B.; Prakash, S.; Chandra, K. Studies on erosion behavior of plasma sprayed coatings on a Ni-based superalloy. Wear 2006, 260, 422-432. [CrossRef]

14. Bircan, B.; Fidan, S.; Çimenoğlu, H. Solid particle erosion behavior of Inconel 718 super alloys under elevated temperatures. Jamme. 2014, 66, 5-12.

15. Liou, J.W.; Lui, T.S.; Chen, L.H. $\mathrm{SiO}_{2}$ particle erosion of A356.2 aluminum alloy and the related microstructural changes. Wear 1997, 211, 169-176. [CrossRef]

16. Hung, F.Y.; Chen, L.H.; Lui, T.S. Phase transformation of an austempered ductile iron during an erosion process. Mater. Trans. 2004, 45, 2981-2986. [CrossRef]

17. Wood, R.J.K.; Walker, J.C.; Harvey, T.J.; Wang, S.; Rajahram, S.S. Influence of microstructure on the erosion and erosion-corrosion characteristics of 316 stainless steel. Wear 2013, 306, 254-262. [CrossRef]

18. Zhao, J.R.; Hung, F.Y.; Lui, T.S. Particle erosion induced phase transformation of different matrix microstructures of powder bed fusion Ti-6Al-4V alloy flakes. Metals 2019, 9, 730. [CrossRef]

19. Chlebus, E.; Gruber, K.; Kuźnicka, B.; Kurzac, J.; Kurzynowski, T. Effect of heat treatment on the microstructure and mechanical properties of Inconel 718 processed by selective laser melting. Mater. Sci. Eng. A 2015, 639, 647-655. [CrossRef]

20. Mostafa, A.; Rubio, I.P.; Brailovski, V.; Jahazi, M.; Medraj, M. Structure, texture and phases in 3D printed IN718 alloy subjected to homogenization and HIP treatments. Metals 2017, 7, 196. [CrossRef]

21. Zhang, S.; Zhao, D. Aerospace Materials Handbook, 1st ed.; CRC Press: Boca Raton, FL, USA, 2013.

22. Lewandowski, M.S.; Sahai, V.; Wilcox, R.C.; Matlock, C.A.; Overfelt, R.A. High temperature deformation of Inconel 718 castings. In Superalloys 718, 625, 706 and Various Dérivatives; Loria, E.A., Ed.; TMS-AIME: Warrendale, PA, USA, 1994; pp. 345-354.

23. Lindsley, B.A.; Marder, A.R. The Effect of velocity on the solid particle erosion rate alloys. Wear 1999, 225-229, 510-516. [CrossRef]

24. Winter, R.E.; Hutchings, I.M. Solid particle erosion srudies using single angular particles. Wear 1974, 29, 181-194. [CrossRef]

25. Liu, F.; Lin, X.; Jeng, H.; Cao, J.; Liu, Q.; Huang, C.; Huang, W. Microstructural changes in a laser solid forming Inconel 718 superalloy thin wall in the deposition direction. Opt. Laser Technol. 2013, 45, 330-335. [CrossRef]

26. SAE Aerospace. Aerospace Material Specification; AMS 5662; SAE International: Warrendale, PA, USA, 2009.

27. Nalawade, S.A.; Sundararaman, M.; Singh, J.B.; Verma, A.; Kishore, R. Precipitation of $\gamma^{\prime}$ phase in $\delta$-precipitated alloy 718 during deformation at elevated temperatures. Mater. Sci. Eng. A 2010, 527, 2906-2909. [CrossRef] 
28. Kuo, C.M.; Yang, Y.T.; Bor, H.Y.; Wei, C.N.; Tai, C.C. Aging effects on the microstructure and creep behavior of Inconel 718 superalloy. Mater. Sci. Eng. A 2009, 510-511, 289-294. [CrossRef]

29. Chamanfar, A.; Sarrat, L.; Jahazi, M.; Asadi, M.; Weck, A.; Koul, A.K. Microstructural characteristics of forged and heat treated Inconel-718 disks. Mater. Design. 2013, 52, 791-800. [CrossRef]

(C) 2019 by the authors. Licensee MDPI, Basel, Switzerland. This article is an open access article distributed under the terms and conditions of the Creative Commons Attribution (CC BY) license (http://creativecommons.org/licenses/by/4.0/). 